\title{
ChemComm
}

This article is part of the

\section{Metal-organic frameworks}

\author{
web themed issue
}

Guest editors: Neil Champness, Christian Serre and Seth Cohen

\begin{abstract}
All articles in this issue will be gathered together online at www.rsc.org/metal-organic-frameworks
\end{abstract}

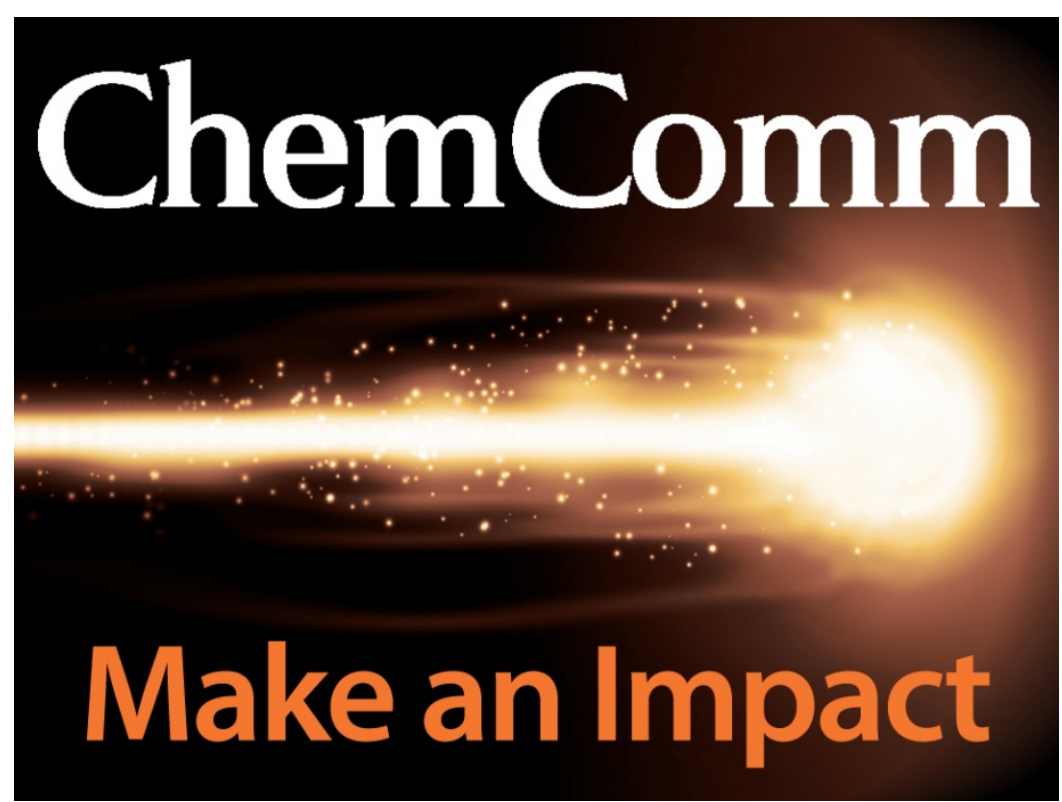




\title{
A new Al-MOF based on a unique column-shaped inorganic building unit exhibiting strongly hydrophilic sorption behaviour $\dagger \neq$
}

\author{
Helge Reinsch, ${ }^{a}$ Bartosz Marszałek, ${ }^{b}$ Julia Wack, $^{c}$ Jürgen Senker, ${ }^{c}$ Barbara Gil $^{b}$ and \\ Norbert Stock $* a$
}

Received 9th July 2012, Accepted 7th August 2012

DOI: $10.1039 / \mathrm{c} 2 \mathrm{cc3} 3909 \mathrm{~d}$

The new Al-based metal-organic framework $\left[\mathrm{Al}_{13}(\mathrm{OH})_{27}\left(\mathrm{H}_{2} \mathrm{O}\right)_{6}-\right.$ $\left(\mathrm{BDC}-\mathrm{NH}_{2}\right)_{3} \mathrm{Cl}_{6}\left(\mathrm{C}_{3} \mathrm{H}_{7} \mathrm{OH}\right)_{6} \mathbf{l}$ denoted CAU-6 (CAU = ChristianAlbrechts-Universität) was solvothermally synthesized in 2-propanol and was thoroughly characterized. The framework structure exhibits a unique column-shaped inorganic building unit, which is based on stacked, corner-sharing $\mathrm{Al}_{13}$-clusters. The compound exhibits unprecedented hydrophilicity for metal-organic frameworks.

Metal-organic frameworks or MOFs are often the subject of research directed towards possible applications in separation processes $^{1}$ as well as in gas storage ${ }^{2}$ and catalysis. ${ }^{3}$ Besides their often unparalleled performances in such areas, they are also investigated regarding their architectural beauty and sometimes unique inorganic building units. $\mathrm{Al}^{3+}$ ions exhibit a rich structural variability in aqueous solutions and many Al-oxo clusters have been reported. ${ }^{4}$ In contrast only a few $\mathrm{Al}^{3+}$ containing building units have been reported for Al-based MOFs synthesized under hydrothermal reaction conditions compared to e.g. $\mathrm{In}^{3+}$-based MOFs. ${ }^{5}$ Besides trimeric and octameric clusters, ${ }^{6,7}$ one-dimensional infinite chains of corner- or edge-sharing $\mathrm{AlO}_{6}$-octahedra ${ }^{8,9}$ as well as continuous two-dimensional layers were observed. ${ }^{10}$ The change of the solvent to methanol induces the stabilization of other structural motifs (Fig. 1). Cyclic cationic clusters based on eight or twelve aluminium ions, i.e. $\left[\mathrm{Al}_{8}(\mathrm{OH})_{4^{-}}\right.$ $\left.\left(\mathrm{OCH}_{3}\right)_{8}\right]^{12+}$ and $\left[\mathrm{Al}_{12}\left(\mathrm{OCH}_{3}\right)_{24}\right]^{12+}$, were shown to be stabilized by the incorporation into a MOF, while they were never observed elsewhere. ${ }^{11,12}$ In principle, these inorganic building units should also be accessible as discrete clusters and vice versa known molecular Al-oxo species could act as inorganic units in MOFs.

Our long-standing interest in the chemistry of Al-based MOFs has been assisted by the use of high-throughput (HT) methods. ${ }^{13}$ Since the structural diversity of this class of compounds is often

\footnotetext{
${ }^{a}$ Institute of Inorganic Chemistry, Christian-Albrechts-Universität Kiel, Max-Eyth-Straße 2, 24118 Kiel, Germany.

E-mail:stock@ac.uni-kiel.de

${ }^{b}$ Faculty of Chemistry, Jagiellonian University, ul. Ingardena 3, 30-060 Kraków, Poland

${ }^{c}$ Inorganic Chemistry I, Universität Bayreuth, Universitätsstaße 30, 95447 Bayreuth, Germany

$\dagger$ This article is part of the ChemComm metal-organic frameworks web themed issue.

$\ddagger$ Electronic supplementary information (ESI) available: Materials and methods, details about synthesis and characterisation, analytical data for Al-MIL-68. See DOI: 10.1039/c2cc34909d
}

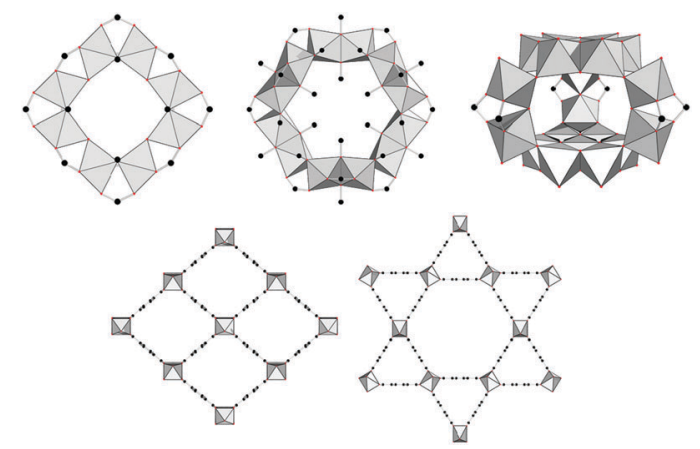

Fig. 1 Structural motifs and framework topologies that are observed in Al-MOFs synthesized from alcohols. Top: inorganic building units in CAU-1 (left), CAU-3 (middle) and CAU-6 (right). Bottom: topologies of MIL-53 (left) and MIL-68 (right).

accompanied by a high sensitivity towards synthesis parameters, these methods have been proven to be very useful for the discovery as well as the synthesis optimization. ${ }^{14,15}$ The new structural motifs observed for the synthesis in methanol inspired us to further employ alcohols as solvents in the system $\mathrm{Al}^{3+}-\mathrm{H}_{2} \mathrm{BDC}-\mathrm{X}$-solvent $\left(\mathrm{H}_{2} \mathrm{BDC}-\mathrm{X}\right.$ stands for benzene-1,4dicarboxylic acid with $\mathrm{X}=\mathrm{H},-\mathrm{NH}_{2}$ ). The use of ethanol yielded the corresponding well known compounds of the MIL-53-family Al-MIL-53 and Al-MIL-53-- $\mathrm{NH}_{2}$ (MIL = Materiaux d'Institute Lavoisier), independently of the aluminium source. Using the more hydrophobic solvent 2-propanol, the use of $\mathrm{AlCl}_{3} \cdot 6 \mathrm{H}_{2} \mathrm{O}$ yielded different framework structures. Employing terephthalic acid, the formation of Al-MIL- $68^{16}$ could be observed (Fig. S2, ESI $\ddagger$ ), while the use of 2-aminoterephthalic acid resulted in the formation of the new compound CAU-6 (Fig. 1). A list of HT reactions carried out and the obtained reaction products are given in the ESI $\ddagger$ (Table S1 and Fig. S1, ESI $\ddagger$ ).

After establishing and optimising the synthetic route by using HT-methods, the reaction was scaled up. In a Teflon-lined autoclave $\left(V_{\text {Max }}=37 \mathrm{~mL}\right), 150 \mathrm{mg}(0.83 \mathrm{mmol})$ of 2-aminoterephthalic acid $\left(\mathrm{H}_{2} \mathrm{BDC}-\mathrm{NH}_{2}\right), 800 \mathrm{mg}$ (3.32 mmol) of $\mathrm{AlCl}_{3}$. $6 \mathrm{H}_{2} \mathrm{O}$ and $5 \mathrm{~mL}$ of 2-propanol were heated for twelve hours to $120{ }^{\circ} \mathrm{C}$, held at this temperature for twelve hours and cooled to room temperature over twelve hours. The precipitate was filtered and redispersed in $300 \mathrm{~mL}$ of water by stirring for several hours. After filtration and drying under ambient conditions, this washing procedure was repeated four more times. 
Upon this treatment, the cell parameters shift slightly (Fig. S3 and S4, ESI $\ddagger$ ).

By a combination of elemental analysis, EDX-spectroscopy, thermogravimetry, IR-spectroscopy and solid-state NMRspectroscopy, the empirical formula of CAU-6 was established to be $\left[\mathrm{Al}_{13}(\mathrm{OH})_{27}\left(\mathrm{H}_{2} \mathrm{O}\right)_{6}\left(\mathrm{BDC}-\mathrm{NH}_{2}\right)_{3} \mathrm{Cl}_{6}\left(\mathrm{C}_{3} \mathrm{H}_{7} \mathrm{OH}\right)_{6}\right]$. For the structure determination, due to the absence of suitable single crystals, high-resolution XRPD data were recorded at the beamline G3 at the DESY-synchrotron source in Hamburg. Indexing of the pattern gave a hexagonal cell, which was confirmed and refined by the Le Bail method, resulting in the cell parameters $a=b=19.2275(3) \AA$ and $c=14.0741(3) \AA$. The extinction conditions are in agreement with the space groups $P \overline{3} 1 c, P \overline{6} 2 c$ and $P 6_{3} / m m c$ (Fig. S10, ESI $\ddagger$ ). The inorganic building unit could be unambiguously identified using direct methods for the structure determination in the space groups $P \overline{3} 1 c$ and $P \overline{6} 2 \mathrm{c} .{ }^{17}$ Both structural models exhibited the higher symmetry of the space group $\mathrm{PG}_{3} / \mathrm{mmc}$. The complete model of the framework was therefore constructed in the space group $P 6_{3} / \mathrm{mmc}$ by insertion of the linker molecules and subsequently optimised using force field calculations. ${ }^{18}$ The framework of CAU-6 is based on the well known $\mathrm{Al}_{13}$-cluster as found in the basic aluminium chloride $\left[\mathrm{Al}_{13}(\mathrm{OH})_{24}\left(\mathrm{H}_{2} \mathrm{O}\right)_{24}\right] \mathrm{Cl}_{15} \cdot 13 \mathrm{H}_{2} \mathrm{O}$ (Fig. 2). ${ }^{19}$ In CAU-6 these clusters are stacked along the $c$-axis and the corner-sharing connectivity leads to the formation of infinite columns (Fig. S13 and S14, ESI†̣). Alternatively, the structure can be described as composed of heptanuclear cores of edge-sharing
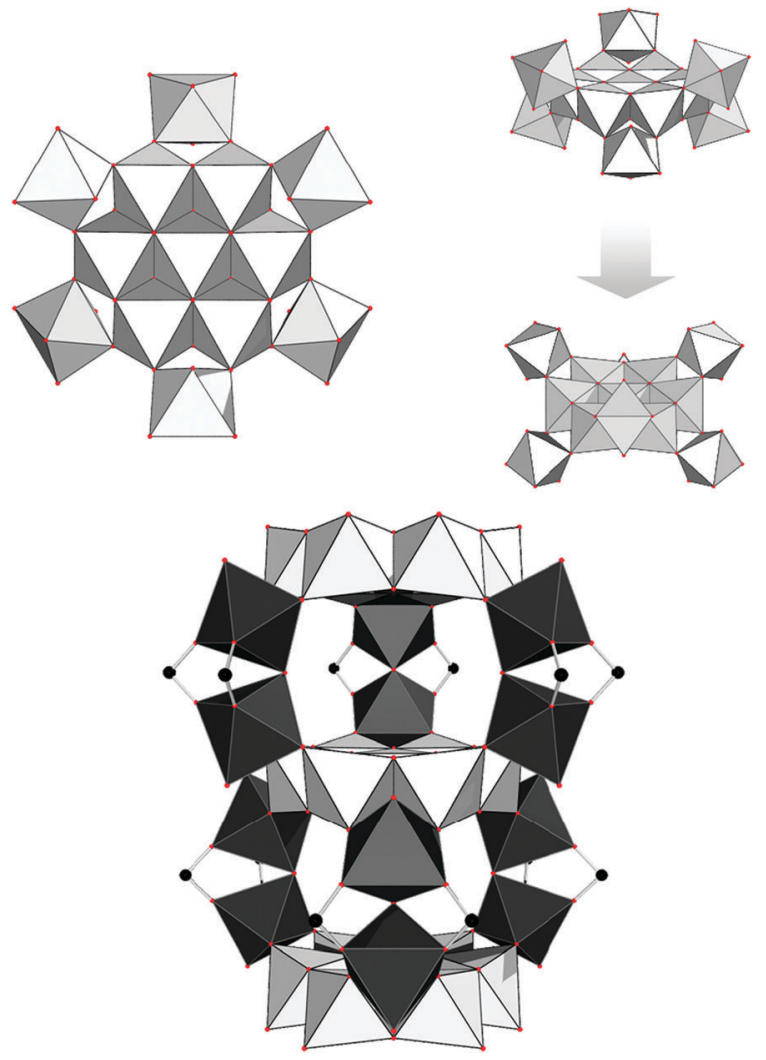

Fig. 2 The $\mathrm{Al}_{13}$-subunit, its mode of condensation and a section of the condensed infinite column as found in the framework of CAU-6. In the latter, heptameric subunits are drawn in light gray, while the bridging dimers are emphasized in black. Bridging carboxylate groups are shown.

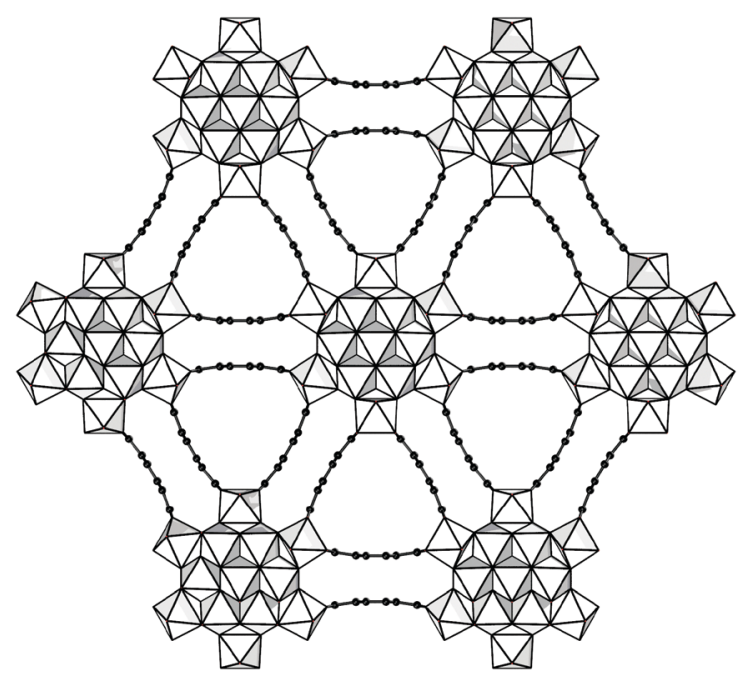

Fig. 3 Framework structure of CAU-6 as seen along the $c$-axis.

$\mathrm{AlO}_{6}$-polyhedra, which are interconnected by dimers of cornersharing $\mathrm{AlO}_{6}$-polyhedra (Fig. 2).

The interconnection of these infinite columns is achieved by aminoterephthalate ions. Two carboxylate groups coordinate to each dimer. Thus, each column is connected to six of their neighbouring columns (Fig. 3). By this connection, sinusoidal trigonal channels with a diameter between 5 and $10 \AA$ are formed. In addition, small cavities with a diameter of $\sim 2.4 \AA$ are found between the heptanuclear cores inside the columns.

These pores are partially occupied by chloride ions, 2-propanol and water molecules in a non-ordered fashion. Therefore, the structural model could not be refined by Rietveld methods, although the simulated pattern is in good agreement with the measured one (Fig. S11, ESI $\ddagger$ ).

The solid-state 1D-NMR-experiments confirm the incorporation of the linker molecules and 2-propanol into the MOF, and prove that the $\mathrm{Al}^{3+}$ ion is exclusively octahedrally coordinated to six oxygen atoms (Fig. S15 and S16, ESI†̣). 2-Propanol molecules could not be removed even by extensive treatment with water and thermal activation at $130{ }^{\circ} \mathrm{C}$. The 2D-NMR-spectrum for ${ }^{27} \mathrm{Al}$ proves that the inorganic unit is built up by $\mathrm{Al}^{3+}$ ions in two different chemical environments in the approximate ratio $7: 6$ (Fig. 4).

This is in good agreement with the structural model. The connection of $\mathrm{Al}^{3+}$ ions within a column must be accomplished by hydroxide ions or solvent molecules. The chloride ions act as counterions. Although some chloride is washed out during the extensive aqueous work-up, residual ions remain inside the channels, as measured by EDX. The occluded water molecules can be only partially removed by thermal activation without damaging the framework structure, as proven by thermogravimetry and in situ IR-spectroscopy (Fig. S6 and S18, ESIț). Thermal treatment in vacuum up to $100{ }^{\circ} \mathrm{C}$ reduces the intensity of the $\nu_{\mathrm{OH}}$-bands of hydrogen bonded water and propanol molecules around $3400 \mathrm{~cm}^{-1}$. The complete removal of water and propanol molecules at temperatures $>150{ }^{\circ} \mathrm{C}$ leads to the decomposition of the framework. This is clearly observed by broadening and flattening of the $\nu_{\mathrm{CO}}$-bands between 1400 and $1700 \mathrm{~cm}^{-1}$. Thus, it is not possible by thermal activation to obtain the solvent-free framework structure without structural 


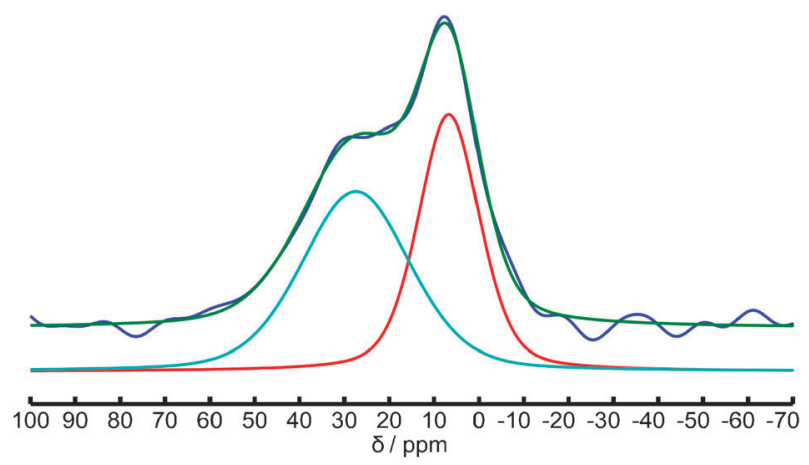

Fig. 4 Deconvoluted F1 projection of the ${ }^{27} \mathrm{Al}$ MQMAS-spectrum. Measured signal (blue) fit (green), simulated signals in red, turquoise.

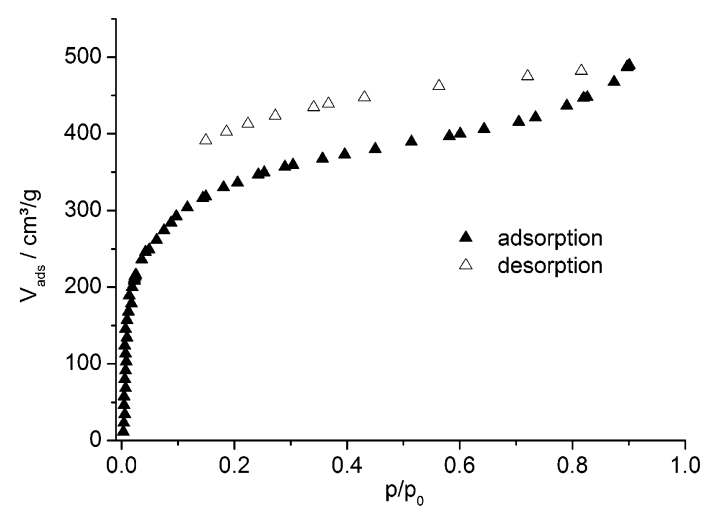

Fig. 5 Water vapour sorption isotherm for CAU-6, measured at $298 \mathrm{~K}$.

collapse. Therefore the residual solvent and water molecules and the counterions must be considered as part of the MOF.

The thermally activated $\left(130{ }^{\circ} \mathrm{C}, 12 \mathrm{~h}, 0.1 \mathrm{mbar}\right)$, i.e. partially dehydrated MOF still exhibits remarkable porosity towards nitrogen (Fig. S8, ESI $\ddagger$ ). The apparent specific BETsurface area is $A_{\mathrm{BET}}=620 \mathrm{~m}^{2} \mathrm{~g}^{-1}$ and the micropore volume is $V_{\text {Mic }}=0.25 \mathrm{~cm}^{3} \mathrm{~g}^{-1}$, as calculated from the amount adsorbed at $p / p_{0}=0.5$. More interestingly, the highly polar surface built up by the protic $\mathrm{OH}$ - and $\mathrm{NH}_{2}$-groups, chloride ions and solvent molecules induces a strong affinity towards polar adsorbents like $\mathrm{CO}_{2}$ (Fig. S9, ESI $\ddagger$ ) and especially towards $\mathrm{H}_{2} \mathrm{O}$ (Fig. 5). The amount of $\mathrm{CO}_{2}$ adsorbed at 1 bar at $298 \mathrm{~K}$ is $V_{\text {ads }}=84 \mathrm{mg} \mathrm{g}^{-1}$.

The type-I-isotherm for the $\mathrm{H}_{2} \mathrm{O}$-vapour adsorption is exceptional for MOFs, and to the best of our knowledge, such hydrophilicity has not been reported for MOFs yet. Most often, MOFs are hydrophobic or require a certain partial pressure, before $\mathrm{H}_{2} \mathrm{O}$ is adsorbed. ${ }^{20-22}$ For CAU-6, the combination of the protic $\mathrm{OH}$ - and $\mathrm{NH}_{2}$-groups, guest molecules and counterions results in hydrophilic properties. Substantial amounts of $\mathrm{H}_{2} \mathrm{O}$-vapour are already adsorbed at low $p / p_{0}$ and the gravimetric capacity at $p / p_{0}=0.9$ is $\sim 37 \%$.

Summarizing the results, we were able to synthesize a new MOF based on unique column-shaped inorganic building units based on $\mathrm{Al}_{13}$-clusters. Although the crystal structure could not be refined by conventional methods, the combination of various analytical techniques allowed us to establish a coherent structural model. The combination of micropores, surface decorating protic groups, solvent molecules and counter ions leads to exceptionally hydrophilic properties.

The research leading to these results has received funding from the European Community's Seventh Framework Programme (FP7/2007-20013) under grant agreement no. 228862. The work has been supported by the DFG (SPP 1362) and the European Regional Development Fund in the framework of the Polish Innovation Economy Operational Program (contract no. POIG.02.01.00-12-023/08). The help of Andre Rothkirch (DESY, Hamburg) during the collection of XRPD-data is gratefully acknowledged, as well as the recording of the SEMmicrographs by Markus Döblinger (LMU Munich).

\section{Notes and references}

1 F. Vermoortele, M. Maes, P. Modhadam, M. Lennox, F. Ragon, M. Boulhout, S. Biswas, K. Laurier, I. Beurroies, R. Denoyel, M. Roeffaers, N. Stock, T. Düren, C. Serre and D. De Vos, J. Am. Chem. Soc., 2011, 133, 18529.

2 M. P. Suh, H. J. Park, T. K. Prasad and D. Lim, Chem. Rev., 2012, 112, 782 .

3 A. Corma, H. García and F. X. Llabrés i Xamena, Chem. Rev., 2010, 110, 4606

4 E. A. Mainicheva, O. A. Gerasko, L. A. Sheludyakova, D. Y. Naumov, M. I. Naumova and V. P. Fedin, Russ. Chem. Bull., 2006, 55, 267.

5 S. Zheng, J. J. Bu, T. Wu, C. Chou, P. Feng and X. Bu, Angew. Chem., Int. Ed., 2011, 50, 8858; S. Zheng, C. Mao, T. Wu, S. Lee, P. Feng and X. Bu, J. Am. Chem. Soc., 2012, 134, 11936.

6 C. Volkringer, D. Popov, T. Loiseau, G. Férey, M. Burghammer, C. Riekel, M. Haouas and F. Taulelle, Chem. Mater., 2009, 21, 5695 .

7 C. Volkringer, D. Popov, T. Loiseau, N. Guillou, G. Ferey, M. Hauuas, F. Taulelle, C. Mellot-Draznieks, M. Burghammer and C. Riekel, Nat. Mater., 2007, 6, 760.

8 T. Loiseau, C. Serre, C. Huguenard, G. Fink, F. Taulelle, M. Henry, T. Bataille and G. Ferey, Chem.-Eur. J., 2004, 10, 1373.

9 C. Volkringer, T. Loiseau, M. Haouas, F. Taulelle, D. Popov, M. Burghammer, C. Riekel, C. Zlotea, F. Cuevas, M. Latroche, D. Phanon, C. Knöfelv, P. L Llewellyn and G. Ferey, Chem. Mater., 2009, 21, 5783.

10 T. Loiseau, L. Lecroq, C. Volkringer, J. Marrot, G. Férey, M. Haouas, F. Taulelle, S. Bourrelly, P. L. Llewellyn and M. Latroche, J. Am. Chem. Soc., 2006, 128, 10223.

11 T. Ahnfeldt, N. Guillou, D. Gunzelmann, I. Margiolaki, T. Loiseau, G. Férey, J. Senker and N. Stock, Angew. Chem., Int. Ed., 2009, 48, 5163.

12 H. Reinsch, M. Feyand, T. Ahnfeldt and N. Stock, Dalton Trans., 2012, 41, 4164.

13 N. Stock, Microporous. Mesoporous. Mater., 2010, 129, 287.

14 H. Reinsch, M. Krüger, J. Wack, J. Senker, F. Salles, G. Maurin and N. Stock, Microporous. Mesoporous. Mater., 2012, 157, 50.

15 A. Sonnauer, F. Hoffmann, M. Fröba, L. Kienle, V. Duppel, M. Thommes, C. Serre, G. Ferey and N. Stock, Angew. Chem., Int. Ed., 2009, 48, 3791.

16 M. Schubert, U. Mueller and S. Marx, Patent US, 2010/0076220 A1, 2010.

17 A. Altomare, M. Cavalli, R. Calandro, C. Cuocci, C. Giacovazzo, A. Gagliardi, A. G. G. Moliterni, R. Rizzi, EXPO2004. Program for Solving Crystal Structures from Powder Data by direct Methods, 2004.

18 Materials Studio Version 5.0, Accelrys Inc., San Diego, CA, 2009.

19 W. Seichter, H. Mögel, P. Brand and D. Salah, Eur. J. Inorg. Chem., 1998, 795.

20 P. Küsgens, M. Rose, I. Senkovska, H. Fröde, A. Henschel, S. Siegle and S. Kaskel, Microporous. Mesoporous. Mater., 2008, 120, 325 .

21 S. K. Henninger, F. Jeremias, H. Kummer and C. Janiak, Eur. J. Inorg. Chem., 2012, 16, 2525.

22 G. Akiyama, R. Matsuda, H. Sato, A. Hori, M. Takata and S. Kitagawa, Microporous. Mesoporous. Mater., 2012, 157, 89. 